\title{
TRATAMENTO DA CRIPTOSPORIDÍASE EM PACIENTES COM AIDS, POR MEIO DA PAROMOMICINA
}

\author{
Haydée Noleto Vasconcelos Stefani, Guido Carlos Levi, Vicente Amato \\ Neto, Lúcia Maria Almeida Braz, Heber Dias Azevedo, Tamea Aparecida \\ Linhares Pôssa, Nanci Ferreira Silva, João Silva de Mendonça e \\ Andréia Otaviani Di Pietro Fernandes
}

\begin{abstract}
A criptosporidiase de 25 pacientes adultos, com sindrome da imunodeficiência adquirida (AIDS) foi tratada por meio da paromomicina, sendo administrados, por via oral, 500mg quatro vezes ao dia, durante duas semanas. Houve boa resposta clinica, representada por redução considerável ou cessação da diarréia em 19 (76\%), tendo a tolerancia sido satisfatória. Somente em um (4\%) doente ocorreram tonturas e, em outro (4\%), surgiram náuseas e vômitos, possivelmente devido à medicação. Controle parasitológico de cura teve lugar em 20 , verificando-se na maioria deles (75\%) persistência do agente causal. Apesar do freqüente insucesso quanto à eliminação do parasita, a melboria obtida na maioria das vezes e a apreciável tolerância ao medicamento, tornam a paromomicina opção muito uitil na terapêtutica da infecção intestinal causada pelo Cryptosporidium sp nos individuos com AIDS.
\end{abstract}

Palavras-chaves: Criptosporidiase. AIDS. Tratamento Paromomicina.

O Cryptosporidium é protozoário intracelular que infecta células epiteliais dos tratos gastrintestinal e respiratório de vertebrados. Motiva comprometimentos comumente autolimitados em imunocompetentes, mas em enfermos com AIDS é freqüente responsável por diarréia crônica e importante perda de peso. A prevalência dessa parasitose nesses pacientes referidos varia consideravelmente segundo as regiões geográficas investigadas; assim, em Nova Iorque é de 10 a 15\%, ao passo que no Haiti sobe para $50 \% \%^{9}$. No Brasil, dado disponível aponta para taxa de 2,7\% Acreditamos, entretanto, que tão baixo índice deva-se a circunstâncias relacionadas com o diagnóstico, nâo refletindo a verdadeira situação.

A terapêutica da diarréia gerada por esse parasita, em geral indicado como Cryptosporidium sp, tem propiciado resultados pouco animadores, com base nos remédios atualmente usados. A espiramicina, considerada

\footnotetext{
Serviço de Doenças Transmissiveis do Hospital do Servidor Público Estadual "Francisco Morato de Oliveira", de São Paulo, e Laboratório de Investigação Médica-Parasitologia do Hospital das Clínicas, da Faculdade de Medicina da Universidade de São Paulo, São Paulo, SP.

Endereço para correspondência: Dr. Guido Carlos Levi. Al. Jaú 759, 01420-001 São Paulo, SP, Brasil.

Recebido para publicação em 12/05/95.
}

a droga mais eficiente até recentemente, permite conseguir porcentagens de sucessos clínicos não superiores a $55 \%$, a par de erradicaçào parasitológica ainda menos habitual e reiteradas recaídas, inclusive quando verificados resultados de início

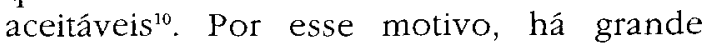
interesse na procura de outros agentes eficientes, valendo lembrar que diclazuril, letrazuril, colostro bovino hiperimune $e$ paromomicina vêm sendo alvos de avaliações promissoras ${ }^{1237581112 .}$

O antibiótico paromomicina é aminoglicosídeo não absorvível pelo intestino. Inibe in vitro a multiplicação do Cryptosporidium e diminui in vivo a excreção fecal dele'. Esta investigação teve o objetivo de verificar a efetividade desse fármaco na coibição da diarréia de pacientes com AIDS e criptosporidíase, tentando colaborar no contexto que envolve afecção oportunista merecedora de aprimoramento terapêutico.

\section{MATERIAL E MÉTODOS}

Constituíram a casuística 25 pacientes adultos, homens e mulheres, com AIDS, atendidos no Serviço de Doenças Transmissiveis do Hospital do Servidor Público Estadual. "Francisco Morato de Oliveira", de São Paulo, no período de março de 1993 a novembro de 1994 . Todos sofriam de diarréia e exames de fezes recentes, 
Stefani HNV, Levi GC, Amato Neto V, Braz LMA, Azevedo HD, Pôssa AL, Silva NF, Mendonça JS, Fernandes AODP. Tratamento da criptosporidiase em pacientes com AIDS, por meio da paromomicina. Revista da Sociedade Brasileira de Medicina Tropical 29:355-357, jul-ago, 1996.

efetuados pelo método de Kinyoun após concentração em água e centrifugação, sistematicamente revelaram a presença de oocistos do Cryptosporidium $\mathrm{sp}^{6}$.

O tratamento consistiu no emprego de $500 \mathrm{mg}$ de paromomicina, por via oral, a cada seis horas, no decurso de 14 dias. Realizamos acompanhamento clínico nessa etapa e subseqüentemente, procurando detectar eventuais recaídas. Empreendemos cuidadosa observação para registrar efeitos colaterais do medicamento e controle laboratorial através de exames de fezes praticados logo após o final do uso do antibiótico, como também 15 dias depois por meio da técnica mencionada.

\section{RESULTADOS}

Em 19 (76\%) doentes observamos resposta clínica, consubstanciada na redução da diarréia ou sua cessação completa. Somente 20 (80\%) efetuaram os controles parasitológicos programados e, quanto aos demais, os exames não puderam ser realizados; três (12\%) em virtude de morte decorrente de outras patologias relacionadas à AIDS e dois (8\%) por não comparecimento às consultas agendadas. Apenas em cinco dos avaliados laboratorialmente verificamos negatividade a propósito da pesquisa do Cryptosporidium. No que tange a 13, apesar da melhoria inicial, reapareceu a diarréia, paralelamente à presença do parasita nas fezes, comprovada semanas ou meses após o tratamento que, quando reinstituído, novamente permitiu benefício sob o ponto de vista clínico.

A tolerância à paromomicina foi boa. Só em dois pacientes ocorreram efeitos colaterais possivelmente ligados ao emprego dela, sendo que em um surgiram tonturas e, no outro, náuseas e vômitos. Essas manifestações assumiram pequenas intensidades e não exigiram a suspensão da administração do antibiótico.

\section{DISCUSSÃO}

Embora o índice de cura parasitológica tenha sido bastante baixo, isso talvez não se afigure surpreendente se recordarmos o que habitualmente acontece em enfermos com AIDS. Também nas pneumocistose, criptococose, histoplasmose, micobacterioses não tuberculosas e candidiase, para citar algumas das patologias mais comuns que afetam esses doentes, a erradicação do agente etiológico é constatada numa minoria das vezes, surgindo freqüentemente reativações ou recaídas provocadas pelo mesmo patógeno.

Assim sendo, embora desejável a obtenção de medicamentos mais eficazes, a porcentagem de respostas clínicas por nós verificada merece valorização, diante do arsenal terapêutico atualmente disponível a respeito da criptosporidíase. Mesmo nos que sofreram recaídas posteriores decorreu período de duração considerável, no qual cessou a diarréia e processou-se melhora no estado geral, geralmente acompanhada por aumento do peso corporal.

Frente aos resultados obtidos no que concerne à interrupção da diarréia ou à percepção de fases, às vezes longas, de ausência desse distúrbio, e levando em conta a tolerância ao medicamento, concluímos que a paromomicina deve ser considerada, presentemente, como cogitável alternativa no âmbito do tratamento de criptosporidiase em doentes com AIDS. No entanto, para aumentar os benefícios que ela pode conceder, é necessário, como em outras infecções oportunistas, empregar esquemas de manutenção para suprimir, a longo prazo, as manifestações clínicas.

Bissuel e cols ${ }^{2}$ relataram recentemente o que fizeram nesse sentido, utilizando quantidades de $500 \mathrm{mg}$ e $1000 \mathrm{mg}$. Tiveram resultados promissores e falhas puderam ser enfrentadas após simples aumento da posologia diária para $2000 \mathrm{mg}$, o que comprova ser a ação da paromomicina, na criptosporidíase, dose dependente. Portanto, serâo importantes novas pesquisas aptas a definir esquemas apropriados à manutenção.

\section{SUMMARY}

The authors treated with paromomycin 25 patients, with AIDS and cryptosporidiasis. The drug was given orally in a doses of $500 \mathrm{mg}$ qid, for a period of 14 days. Tolerance was good, with just two cases of mild side-effects. Clinical improvement was obtained in 19 (76\%) patients. Parasitological cure, bowever, occurred only in a low percentage (25\%). In some cases where initial success was observed, recrudescence occurred after some weeks or few montbs, but with retreatment again clinical improvement was obtained. Even if it does not lead to frequent parasite eradication, the good clinical 
Stefani HNV, Levi GC, Amato Neto V, Braz LMA, Azevedo HD, Pôssa AL, Silta NF, Mendonça JS, Fernandes AODP. Tratamento da criptosporidíase en pacientes com AIDS, por meio da paromomicina. Revista da Sociedade Brasileira de Medicina Tropical 29:355-357, jul-ago, 1996.

results and tolerance permit us to consider paromomycin one of the few drugs effective for the treatment of cryptosporidial diarrbea in AIDS patients. Studies with maintainance therapy are indicated.

Key-words: Cryptosporidiasis. AIDS. Treatment. Paromomycin

\section{REFERÊNCIAS BIBLIOGRÁFICAS}

1. Armitage $K$, Flanigan $T$, Carey $J$, Frank $I$, MacGregor RR, Ross P, Goodgame R, Turner J. Treatment of cryptosporidiosis with paromomycin. A report of five cases. Archives of Internal Medicine 152:2497-2499, 1982.

2. Bissuel $R$, Cotte $L$, Rabodonirina $M$, Rougier $P$, Piens M-A, Trepo C. Paromomycin: an effective treatment for cryptosporidial diarrhea in patients with AIDS. Clinical Infectious Diseases 18:447449, 1994 .

3. Borowitz SM, Saulsbury FT. Treatment of chronic cryptosporidial infection with orally administered human serum immune globulin. The Journal of Pediatrics 119:593-595, 1991.

4. Connoly GM, Youle M, Gazzard BG. Diclazuril in the treatment of severe cryptosporidial diarthea in AIDS patients. AIDS 4:700-701, 1990.

5. Fichtenbaum CJ, Ritchie DJ, Powderly WG. Use of paromomycin for treatment of cryptosporidiosis in patients with AIDS. Clinical Infectious Diseases 16:298-300, 1993.

6. Ma P, Soave R. Three-step stool examination for cryptosporidiosis in 10 homosexual men with protracted watery diarrhea. The Journal of Infectious Diseases 147:824-828, 1983.

7. Ministério da Saúde. AIDS Boletim Epidemiológico.Ano VII, $\mathrm{N}^{\circ} 3,9$ a 13 de março de 1994, Brasilia, DF, Brasil.

8. Nord J, Ma P, DiJohn D, Tzipori S, Tacket CO. Treatment with bovine hiperimmune colostrum of cryptosporidial diarrhea in AIDS patients. AIDS 4:581-584, 1990.

9. Petersen C. Cryptosporidiosis in patients infected with the human immunodeficiency virus. Clinical Infectious Diseases 15:903-909, 1992.

10. Portnoy D, Whiteside ME, Buckley E. Treatment of intestinal cryptosporidiosis with spiramycin. Annals of Internal Medicine 101:202, 1984.

11. Ritchie DJ, Becker ES. Update on the management of intestinal cryptosporidiosis in AIDS. The Annals of Pharmacotherapy 28:767-778, 1994.

12. White Jr AC, Chapell CL, Hayat CS, Kimball KT, Flanigan TP, Goodgame RW. Paromomycin for cryptosporidiosis in AIDS: a prospective, doubleblind trial. Journal of Infectious Diseases 170:419424, 1994. 